\title{
The Levels of FoxO3a Predict the Failure of Imatinib Mesylate Therapy among Chronic Myeloid Leukemia Patients
}

\author{
Shinta Oktya Wardhani ${ }^{1 *}$, Hani Susianti ${ }^{2}$, Puji Rahayu ${ }^{3}$, Yuyun Yueniwati ${ }^{4}$, Jonny Karunia Fajar $^{5}$ \\ ${ }^{1}$ Doctoral Program in Medical Science, Division of Hematology and Oncology, Department of Internal Medicine, Faculty of \\ Medicine, Universitas Brawijaya, Malang 65145, Indonesia; ${ }^{2}$ Department of Clinical Pathology and Laboratory Medicine, \\ Faculty of Medicine, Universitas Brawijaya, Malang 65145, Indonesia; ${ }^{3}$ Department of Otorhinolaryngology, Faculty of \\ Medicine, Universitas Brawijaya, Malang 65145, Indonesia; ${ }^{4}$ Department of Radiology, Faculty of Medicine, Universitas \\ Brawijaya, Malang 65145, Indonesia; ${ }^{5}$ Department of Internal Medicine, Brawijaya Internal Medicine Research Center, Faculty \\ of Medicine, Universitas Brawijaya, Malang 65145, Indonesia
}

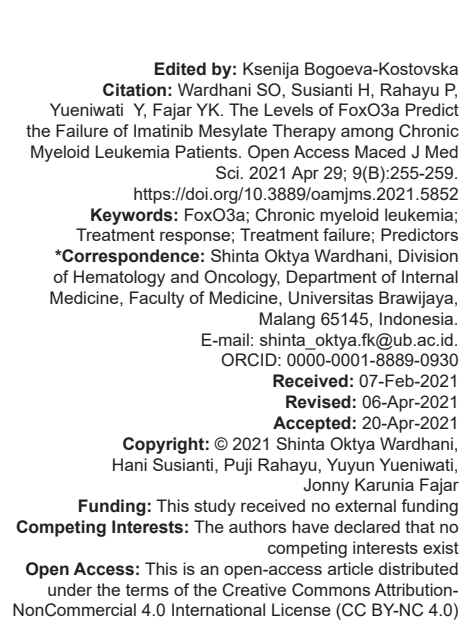

Introduction

Chronic myeloid leukemia (CML), a clonal myeloproliferative disorder of hematopoietic stem cells, is the major hematological health problem [1]. The incidence of this disease was reported between 0.7 and 1.0 per 100,000 population [2]. Of them, the mortality was $<15 \%$ [3]. The standard guideline for the management of CML has been established. In the guideline, tyrosine kinase inhibitors (TKIs) are used for treating patients with CML, and among all TKIs, imatinib mesylate (IM) is the most often used and approved by the US Food and Drug Administration (FDA) for the frontline therapy of CML patients [4]. The evidence revealed that, since IM therapy was introduced, the survival rate of $\mathrm{CML}$ patients increased to approximately $87 \%$ [3]. Briefly, imatinib binds to the BCR-ABL protein tyrosine kinase (the inactive conformation), and thereafter may prevent the conformational switching of BCR-ABL protein by blocking the ATP binding site [5]. However, IM therapy was accompanied by numerous challenges. One of them was treatment failure [1]. The case of imatinib resistance has been reported, and the heterogeneous mechanism is proposed to underlie this resistance including BCR-ABL gene amplification and gene mutation which may lead to incomplete inhibition [6]. Previous studies had proposed some markers that might predict the treatment response of IM therapy including human organic cation transporter 1, patched homolog 1, prostaglandin-endoperoxide synthase 1, cyclooxgenase 1 , and forkhead transcription factor 3a (FOXO3a) [7], [8], [9]. Of those, the role of FoxO3a had limited evidence.

FOXO3a belongs to the FOXO subfamily of forkhead transcription factors. In human, the FOXO transcription factors are encoded by five genes, including FOXO1, FOXO3a, FOXO3b, FOXO4, and FOXO6 [10]. In the context of cancer, the physiological function of FoxO3a is to stimulate some cellular mechanism including 
proliferation, apoptosis, DNA damage, the activation of reactive oxygen species, cell cycle progression, and tumorigenesis [11], [12]. Several studies had proposed that FoxO3a might provide a high accuracy to predict the treatment response of IM therapy in CML patients [13], [14]. However, the lack evidence of real world study regarding the role of $\mathrm{FoxO} 3 \mathrm{a}$ in predicting the treatment response of $\mathrm{CML}$ therapy has made the precise role of this marker remains controversy. Moreover, in Indonesia, no study reported the role of FoxO3a in predicting the treatment response of IM therapy. Therefore, our current study aimed to investigate the potential role of FoxO3a to estimate the treatment failure of IM therapy among CML patients. The findings of our current study might serve as the initial evaluation for treatment response of IM therapy, and thereafter treatment failure of IM therapy might be anticipated.

\section{Methods}

\section{Study design and patients}

A prospective cohort study was carried out in Saiful Anwar General Hospital between February 2019 and February 2020. We used total sampling method to recruit the patients (a total of 26 participants in each study group were needed as the minimum sample size according to the estimation that the prevalence of CML was $10-12$ per 100,000 inhabitants with a $5 \%$ margin of error and 95\% confidence level) [15]. The inclusion criteria were: (1) All CML patients treated in our hospital during the study period (the diagnosis criteria were adapted from previous study) [16], (2) CML patients treated with standard IM $400 \mathrm{mg} / \mathrm{day}$ for at least 6 months [17], (3) aged more than 18 years old, and (4) providing the written informed consent to participate in the study. The exclusion criteria were (1) patients treated with other TKI medications, (2) patients with drugs consumption that may reduce the efficacy of IM such as prazosin, proton pump inhibitors, and erythromycin, and (3) patients suffering from diseases that may associate with increased levels of FoxO3a such as chronic obstructive pulmonary disease (COPD), vitiligo, prostate cancer, thyroid, breast, and gynecological cancer. This study had been approved by the local (Universitas Brawijaya) Ethical Committee (No. 400/098 / k.3 / 302/2019) and had been conducted following the code of ethics of Helsinki declaration.

\section{Outcome measures}

The predictor covariate in our study was the levels of FoxO3a. The levels of FoxO3a were measured by the Enzyme-linked immunosorbent assay using Cusabio Biotech Kit (Cusabio Biotech Co., New York, USA) following the manufacture instruction as described by the previous study [18], [19]. The levels of FoxO3a were measured in picogram/milliliter $(\mathrm{pg} / \mathrm{mL})$ units. On the other hands, the outcome measures were the treatment response of IM therapy assessed using the European Leukemia Net milestone 2020 criteria [20]. Patients were defined failure response if the Bcr-Abl was more than $10 \%$, measured using the real-time polymerase chain reaction after 6 months of IM therapy, or after 3 months of IM therapy and reconfirmed within 3 months (6 months). Moreover, we also assessed the complete blood count, measured using XS - 800i Hematology Analyzer (Sysmex Europe $\mathrm{GmbH}$, Norderstedt, Germany).

\section{Statistical analysis}

The correlation between treatment response of IM therapy and their predictors was assessed using multiple logistic regressions. $p<0.05$ indicated the significant association. We used Statistical Package for the Social Sciences 17.0 software (SPSS Inc., Chicago, IL) to analyze the data [21].

\section{Results}

\section{Patients characteristics}

A total of $53 \mathrm{CML}$ patients treated with IM were analyzed. Of them, a total of $29(55 \%)$ patients successfully achieved treatment response and 24 $(45 \%)$ subjects did not achieve treatment response. Initially, we evaluated a total of $61 \mathrm{CML}$ patients treated with IM. However, we excluded a total of eight patients due to having the history of drugs consumption that may reduce the effectiveness of IM (proton pump inhibitors) and suffering from diseases that are known to associate with increased levels of FoxO3a (COPD). Our study participants between two groups were age and sex matched (Table 1).

Table 1: Baseline characteristics of patients included in our study

\begin{tabular}{llll}
\hline Characteristics & Non-achieved (24) & Achieved $(\mathrm{n}=29)$ & $\mathrm{p}$ \\
\hline Age (years) & $43.67 \pm 13.90$ & $43.03 \pm 11.43$ & 0.780 \\
Male & $12(50.0)$ & $15(51.7)$ & 0.901 \\
Clinical phase & & & \\
$\quad$ Chronic phase & $8(33.3)$ & $23(79.3)$ & 0.001 \\
$\quad$ Advanced phase & $16(66.7)$ & $6(20.7)$ & 0.001 \\
$\begin{array}{l}\text { SOKAL risk score } \\
\quad \text { Intermediate risk }\end{array}$ & $5(20.8)$ & $11(37.9)$ & 0.182 \\
$\quad$ High risk & $19(79.2)$ & $18(62.1)$ & 0.182 \\
$\begin{array}{l}\text { EUTOS risk score } \\
\text { Low risk }\end{array}$ & $16(66.7)$ & $29(100.0)$ & 0.022 \\
$\quad$ High risk & $8(33.3)$ & $0(0.0)$ & 0.022 \\
$\quad$ Duration of therapy (months) & $6.90 \pm 0.88$ & $6.98 \pm 1.20$ & 0.727 \\
$\quad \begin{array}{l}\text { Combination with } \\
\text { hydroxyurea }\end{array}$ & $2(14.3)$ & $0(0.0)$ & 0.232 \\
\hline Data were presented in $\mathrm{n}(\%)$ or mean \pm SD. & & \\
$\quad$
\end{tabular}

\section{Main findings}

Our results identified that the levels of thrombocytes, hemoglobin, basophils, leukocytes, 
$\mathrm{CD} 26+$, and FoxO3a contributed to treatment response of CML patients treated with IM. We found that patients with elevated levels of thrombocytes, basophils, and leukocytes were significantly found in non-response group compared to response group. Moreover, our findings also revealed that lower levels of hemoglobin and FoxO3a were correlated with increased risk of failure response of CML patients treated with IM (Table 2).

Table 2: Laboratory parameters and the levels of FoxO3a among chronic myeloid leukemia patients

\begin{tabular}{llllll}
\hline Parameters & Non-achieved & Achieved & OR & $95 \% \mathrm{Cl}$ & $\mathrm{p}$ \\
\hline Hemoglobin (gr/dl) & $10.43 \pm 3.28$ & $12.61 \pm 1.84$ & 0.23 & $0.09-0.65$ & 0.005 \\
Leukocytes (cells/ul) & $91580 \pm 141888$ & $6849 \pm 2652$ & 5.02 & $1.79-14.02$ & 0.002 \\
Thrombocytes (cells/ul) & $303125 \pm 238699$ & $191103 \pm 112808$ & 3.08 & $1.13-8.40$ & 0.028 \\
Basophils (abs) & $1.20 \pm 1.61$ & $0.00 \pm 0.25$ & 7.33 & $2.56-20.99$ & 0.001 \\
Blast cells (abs) & $9.21 \pm 12.83$ & $6.00 \pm 7.66$ & 1.76 & $0.65-4.71$ & 0.264 \\
BCR-ABL & $28.09 \pm 16.64$ & $747.78 \pm 40.16$ & 0.65 & $0.24-1.73$ & 0.383 \\
FoxO3a (pg/mL) & $42.12 \pm 41.21$ & $80.79 \pm 50.50$ & 0.22 & $0.08-0.61$ & 0.004 \\
\hline Data were presented in mean \pm SD. & & & &
\end{tabular}

\section{Discussion}

Our study found that the levels of FoxO3a were the significant predictor for assessing the treatment response of $\mathrm{IM}$ therapy among $\mathrm{CML}$ patients. We found that lower levels of FoxO3a were associated with the failure of IM therapy in CML patients. Our current findings were consistent with the reports of previous studies [22]. They also found that FoxO3a was the important predictors of treatment failure among $\mathrm{CML}$ patients treated with IM. The potential role of FoxO3a for predicting the treatment response had been widely proposed [11], [13]. Theoretically, it has been known that FoxO3a plays a crucial role in the pathogenesis of CML. Through the phosphatidyl-inositol 3-OH kinase/AKT pathway, FoxO3a may establish the phosphorylation by $\mathrm{p} 210 \mathrm{BCR}-\mathrm{ABL}$ tyrosine kinase, and may contribute to the proliferative of leukemic progenitors [23]. On the other hand, the inhibition of IM may interrupt the cell cycle progression and apoptosis of CML cells, and thereafter may restore the function of FoxO3a [24]. Moreover, the inhibition of Bcr-Abl kinase by IM causes the activation of FoxO3a that may further induce Bim expression through FoxO3a binding site, and therefore increases the apoptosis [24]. Another study also confirmed that FoxO3a not only induced apoptosis of leukemic stem cells but also induced arrest of the cell cycle [25]. Therefore, the lower levels of FoxO3a might play a prominent role to predict the treatment response among $\mathrm{CML}$ patients treated with IM as reported in our study.

Our findings also clarified that CML patients with increased levels of thrombocytes, basophils, and leukocytes and the lower levels of hemoglobin had a higher risk to develop treatment failure after treated with IM. Our results were in line with the report of previous studies. The altered levels of thrombocytes, basophils, leukocytes, and hemoglobin were also reported to affect the treatment response of IM therapy. A study revealed that, in the 1 year of treatment response among $\mathrm{CML}$ patients treated with $\mathrm{IM}$, patients with non-response of IM therapy had the higher levels of leukocyte compared to response group. Furthermore, they also revealed that the levels of leukocyte prior the treatment was associated with the prognosis of CML patients, suggesting that leukocyte may play a crucial role to govern the treatment of CML patients [26]. On the other hand, the lower levels of thrombocyte in response group compared to non-response group in our present study were also supported by the previous studies. They also found that higher levels of thrombocyte were found to associate with non-response of CML patients treated with IM [27], [28]. Furthermore, the previous study also supported our findings that the levels of basophils also governed the treatment response of $\mathrm{CML}$ patients treated with IM. They revealed that basophils might produce the autocrine growth factor for myeloid, and therefore, might attribute to the treatment response of CML patients [29], [30]. Moreover, lower levels of hemoglobin in our present study were associated with increased risk of treatment failure on CML patients treated with IM. The previous studies had also supported our findings. They found that anemic patients who received IM therapy were associated with lower rate of cytogenic remission and shorter progression free survival [31], [32].

Our present study was the first report concerning the role of FoxO3a on predicting the treatment response of CML patients treated with IM in Indonesia. Our current finding might serve as the baseline evaluation to predict the treatment response of IM therapy. In the near future, our current findings might contribute to the improvement of IM therapy procedure in CML patients, and therefore, treatment failure of IM therapy for the management of CML patients could be prevented.

In our present study, several limitations should be discussed. First, several factors that might contribute to the severity and treatment response of CML patients treated with IM including the adherence of medication, smoking, physical activity, and dietary factors were not analyzed [33]. Second, the small sample size in our present study might drive to the false positive findings, and therefore, our findings should be interpreted with caution. Third, the short-term period of follow-up in our present study might not adequate to elucidate the real association.

\section{Conclusion}

Our study clarifies that the levels FoxO3a and hematological parameters including the levels of thrombocytes, basophils, leukocytes, and hemoglobins are the predictors of treatment failure of CML patients treated with IM. These parameters, in the near future, might be used as the initial evaluation of IM therapy for the management of CML patients. 


\section{Declarations}

\section{Ethics approval and consent to participate}

Participants had provided written informed consent prior to involve in the study. Our study had been approved by local ethical committee (No. 400/098 / k.3 / 302/2019).

\section{Availability of data and materials} main text.

Data used in our study were presented in the

\section{Acknowledgment}

We thank to RSUD dr. Saiful Anwar \& Universitas Brawijaya for supporting this project.

\section{Authors Contributions}

Idea/concept: SOW. Design: SOW and JKF. Control/supervision: SOW, HS, PR, and YY. Data collection/processing: SOW and JKF. Extraction/ Analysis/interpretation: SOW and JKF. Literature review: SOW and JKF. Writing the article: SOW and JKF. Critical review: SOW, HS, PR, and YY. All authors have critically reviewed and approved the final draft and are responsible for the content and similarity index of the manuscript.

\section{References}

1. Flis S, Chojnacki T. Chronic myelogenous leukemia, a still unsolved problem: Pitfalls and new therapeutic possibilities. Drug Des Devel Ther. 2019;13:825-43. https://doi.org/10.2147/ dddt.s191303

PMid:30880916

2. Hoglund M, Sandin F, Simonsson B. Epidemiology of chronic myeloid leukaemia: An update. Ann Hematol. 2015;94 Suppl 2:S241-7. https://doi.org/10.1007/s00277-015-2314-2 PMid:25814090

3. Granatowicz A, Piatek $\mathrm{Cl}$, Moschiano E, El-Hemaidi I, Armitage JD, Akhtari M. An overview and update of chronic myeloid leukemia for primary care physicians. Korean J Fam Med. 2015;36(5):197-202. https://doi.org/10.4082/ kjfm.2015.36.5.197 PMid:26435808

4. Baccarani M, Pileri S, Steegmann JL, Muller M, Soverini S,
Dreyling $\mathrm{M}$, et al. Chronic myeloid leukemia: ESMO clinical practice guidelines for diagnosis, treatment and follow-up. Ann Oncol. 2012;23 Suppl 7:vii72-7. https://doi.org/10.1093/annonc/ mds228

PMid:22997458

5. An X, Tiwari AK, Sun Y, Ding PR, Ashby CR Jr., Chen ZS. BCR$A B L$ tyrosine kinase inhibitors in the treatment of Philadelphia chromosome positive chronic myeloid leukemia: A review. Leuk Res. 2010;34(10):1255-68. https://doi.org/10.1016/j. leukres.2010.04.016

PMid:20537386

6. Bitencourt R, Zalcberg I, Louro ID. Imatinib resistance: A review of alternative inhibitors in chronic myeloid leukemia. Rev Bras Hematol Hemoter. 2011;33(6):470-5. https://doi. org/10.5581/1516-8484.20110124 PMid:23049365

7. Clark RE, Davies A, Pirmohamed M, Giannoudis A Pharmacologic markers and predictors of responses to imatinib therapy in patients with chronic myeloid leukemia. Leuk Lymphoma. 2008;49(4):639-42. https://doi. org/10.1080/10428190701858823

PMid:18398725

8. Alonso-Dominguez JM, Casado LF, Anguita E, GomezCasares MT, Buño I, Ferrer-Marín F, et al. PTCH1 is a reliable marker for predicting imatinib response in chronic myeloid leukemia patients in chronic phase. PLoS One. 2017;12(7):e0181366. https://doi.org/10.1371/journal. pone. 0181366

PMid:28704552

9. Stefanetti RJ, Voisin S, Russell A, Lamon S. Recent advances in understanding the role of FOXO3. F1000Res. 2018;7:F1000 Faculty Rev-1372. https://doi.org/10.12688/ f1000research.15258.1 PMid:30228872

10. Schmitt-Ney M. The FOXO's advantages of being a family: Considerations on function and evolution. Cells. 2020;9(3):787. https://doi.org/10.3390/cells9030787 PMid:32214027

11. Liu Y, Ao X, Ding W, Ponnusamy M, Wu W, Hao X, et al. Critical role of FOXO3a in carcinogenesis. Mol Cancer. 2018;17(1):104. https://doi.org/10.1186/s12943-018-0856-3 PMid:30045773

12. Liou GY, Storz P. Reactive oxygen species in cancer. Free Radic Res. 2010;44(5):479-96. PMid:20370557

13. Corrado P, Mancini M, Brusa G, Petta S, Martinelli G, Barbieri E, et al. Acetylation of $\mathrm{FOXO} 3$ a transcription factor in response to imatinib of chronic myeloid leukemia. Leukemia. 2009;23(2):4056. https://doi.org/10.1038/leu.2008.186 PMid: 18685617

14. Pellicano F, Scott MT, Helgason GV, Hopcroft LE, Allan EK, Aspinall-O'Dea M, et al. The antiproliferative activity of kinase inhibitors in chronic myeloid leukemia cells is mediated by FOXO transcription factors. Stem Cells. 2014;32(9):2324-37. https://doi.org/10.1002/stem.1748 PMid:24806995

15. Charan J, Biswas T. How to calculate sample size for different study designs in medical research? Indian J Psychol Med. 2013;35(2):121-6. https://doi.org/10.4103/0253-7176.116232 PMid:24049221

16. Haznedaroglu IC, Kuzu I, Ilhan O. WHO 2016 definition of chronic myeloid leukemia and tyrosine kinase inhibitors. Turk J Haematol. 2020;37(1):42-7. https://doi.org/10.4274/tjh. galenos.2019.2019.0241 


\section{PMid:31612694}

17. Kantarjian HM, Larson RA, Guilhot F, O'Brien SG, Mone M, Rudoltz M, et al. Efficacy of imatinib dose escalation in patients with chronic myeloid leukemia in chronic phase. Cancer. 2009;115(3):551-60. https://doi.org/10.1002/cncr.24066 PMid:19117345

18. Zhang S, Zhao Y, Xu M, Yu L, Zhao Y, Chen J, et al. FoxO3a modulates hypoxia stress induced oxidative stress and apoptosis in cardiac microvascular endothelial cells. PLoS One. 2013;8(11):e80342. https://doi.org/10.1371/journal. pone.0080342

PMid:24278276

19. Kalemci S, Edgunlu TG, Turkcu U, Çetin ES, Zeybek A, Candan $\mathrm{H}$. FOXO3a gene polymorphism and serum FOXO3a levels in patients with chronic obstructive pulmonary disease and healthy controls: Effects of genetic polymorphism in chronic obstructive pulmonary disease. Smyrna Med J. 2014;1:1-5. https://doi.org/10.5114/kitp.2014.45682

20. Hochhaus A, Baccarani M, Silver RT, Schiffer C, Apperley JF, CervantesF, etal.European LeukemiaNet2020 recommendations for treating chronic myeloid leukemia. Leukemia. 2020;34(4):96684. https://doi.org/10.1038/s41375-020-0776-2 PMid:32127639

21. Kim HY. Statistical notes for clinical researchers: Logistic regression. Restor Dent Endod. 2017;42(4):342-8. https://doi. org/10.5395/rde.2017.42.4.342

PMid:29142883

22. Wagle M, Eiring AM, Wongchenko M, Lu S, Guan Y, Wang Y, et al. A role for FOXO1 in BCR-ABL1-independent tyrosine kinase inhibitor resistance in chronic myeloid leukemia. Leukemia. 2016;30(7):1493-501. https://doi.org/10.1038/leu.2016.51 PMid:27044711

23. Komatsu N, Watanabe T, Uchida M, Mori M, Kirito K, Kikuchi S, et al. A member of Forkhead transcription factor FKHRL1 is a downstream effector of STI571-induced cell cycle arrest in BCR-ABL-expressing cells. J Biol Chem. 2003;278(8):6411-9. https://doi.org/10.1074/jbc.m211562200 PMid:12456669

24. Essafi A, de Mattos SF, Hassen YA, Soeiro I, Mufti GJ, Thomas NS, et al. Direct transcriptional regulation of Bim by FoxO3a mediates STI571-induced apoptosis in Bcr-Ablexpressing cells. Oncogene. 2005;24(14):2317-29. https://doi. org/10.1038/sj.onc.1208421 PMid:15688014

25. Yang JY, Hung MC. Deciphering the role of forkhead transcription factors in cancer therapy. Curr Drug Targets. 2011;12(9):1284-90. https://doi.org/10.2174/138945011796150299

PMid:21443462

26. Qin $Y Z$, Jiang $Q$, Jiang $H$, Lai $Y Y$, Zhu $H H$, Liu $Y R$, et al. Combination of white blood cell count at presentation with molecular response at 3 months better predicts deep molecular responses to imatinib in newly diagnosed chronic-phase chronic myeloid leukemia patients. Medicine (Baltimore). 2016;95(2):e2486. https://doi.org/10.1097/ md.0000000000002486

PMid:26765457

27. Assouline $\mathrm{S}$, Lipton $\mathrm{JH}$. Monitoring response and resistance to treatment in chronic myeloid leukemia. Curr Oncol. 2011;18(2):e71-83. https://doi.org/10.3747/co.v18i2.391 PMid:21505592

28. Cortes J, Quintas-Cardama A, Kantarjian HM. Monitoring molecular response in chronic myeloid leukemia. Cancer. 2011;117(6):1113-22. https://doi.org/10.1002/cncr.25527 PMid:20960522

29. El-Ghammaz AM, Hamed GM, Fattah MF, Attia MH. Basophil progenitor marker histamine and its relation to the treatment response in Egyptian chronic myeloid leukemia patients. Egypt J Haematol. 2015;40:30. https://doi. org/10.4103/1110-1067.155793

30. Valent P, Horny HP, Arock M. The underestimated role of basophils in $\mathrm{Ph}(+)$ chronic myeloid leukaemia. Eur J Clin Invest. 2018;48(10):e13000. https://doi.org/10.1111/eci.13000 PMid:30019447

31. Moura MS, Benevides TC, Delamain MT, Duarte GO, Percout PO, Dias MA, et al. Evaluation of anemia after longterm treatment with imatinib in chronic myeloid leukemia patients in chronic phase. Hematol Transfus Cell Ther. 2019;41(4):32934. https://doi.org/10.1016/j.htct.2019.03.006

PMid:31395459

32. Jabbour E, le Coutre PD, Cortes J, Giles F, Bhalla KN, PinillaIbarz J, et al. Prediction of outcomes in patients with $\mathrm{Ph}+$ chronic myeloid leukemia in chronic phase treated with nilotinib after imatinib resistance/intolerance. Leukemia. 2013;27(4):907-13. https://doi.org/10.1038/leu.2012.305 PMid:23174881

33. Kabat GC, Wu JW, Moore SC, Morton LM, Park Y, HollenbeckAR, et al. Lifestyle and dietary factors in relation to risk of chronic myeloid leukemia in the NIH-AARP diet and health study. Cancer Epidemiol Biomarkers Prev. 2013;22(5):848-54. https:// doi.org/10.1158/1055-9965.epi-13-0093

PMid:23625904 